\title{
Metformin Associated Interleukin-10 Affected Insulin Sensitivity and Anti-Tuberculosis Result in Type 2 Diabetes with Tuberculosis Co- infection: A Case Report
}

\section{Bernadette Dian Novita*}

Departement of Pharmacology and Therapy, Faculty of Medicine, Widya Mandala Catholic University Surabaya, Indonesia

*Corresponding author: Novita BD, Department of Pharmacology and Therapy, Faculty of Medicine, Widya Mandala Catholic University Surabaya, Indonesia, Tel: +62-812-3547540; E-mail: diannovitakrisdianto@yahoo.co.id

Received date: April 6, 2018; Accepted date: April 10, 2018; Published date: April 16, 2018

Copyright: ( 2018 Novita BD. This is an open-access article distributed under the terms of the Creative Commons Attribution License, which permits unrestricted use, distribution, and reproduction in any medium, provided the original author and source are credited.

\begin{abstract}
Insulin is one of drug of choice in lowering blood glucose in diabetes patients with or without infection. Interleukin (IL)-10 an anti-inflammatory cytokine, plays a protective role in diabetes. The lack of IL-10 associated to development and progression of insulin resistance. On the other hands, Interferon (IFN)- $\mathrm{Y}$ elevation is one of the indicators of successful treatment in active TB infection and IL-10 inhibits IFN-Y secretion. Metformin has ability in increasing insulin response and also has protective effect against TB in DM patients. However the relationship between metformin and insulin induced IL-10 and metformin enhanced anti tuberculosis remains unclear.
\end{abstract}

Keywords: Insulin; Type 2 diabetes; Tuberculosis

\section{Introduction}

Tuberculosis (TB) nowadays is one of "global health emergency" diseases [1]. Diabetes mellitus (DM), a dysfunction metabolic disease affecting immune response carries a two to threefold increased risk for TB in these patients over patients without DM [2-4]. High interferon (IFN) $-\gamma$ is an indicator of anti-tuberculosis (TB) successful TB eradication due to its ability in modulating the production or activities of several cytokines and chemokines [5-8]. Low IL-10 plays a critical role in the development and progression of insulin resistance $[9,10]$. However, IL-10 reduces the function of macrophages and dendritic cells by inhibiting IFN $-\gamma[6,11]$.

Metformin hydrochloride (MET), biguanide, use in type 2 diabetes mellitus by several mechanisms of action (1) inhibiting gluconeogenesis or hepatic glucose production; (2) reducing intestinal glucose absorption; and (3) improving glucose uptake and utilization [12-15]. MET also has protective effect in TB patients and recently, by a comprehensive in silico study, MET known has possibilities of controlling the growth of drug-resistant M.tuberculosis strains via production of mitochondrial reactive oxygen species and facilitates phagosome-lysosome fusion [16] and its immunomodulation effect $[17,18]$.

\section{Materials and Methods}

\section{Study design}

This involved type 2 DM-TB co-infection patients of observational clinical study within two groups, observation group, and the comparison group. The observation group (MET group) was the group receiving metformin therapy $1000 \mathrm{mg}$ to $1500 \mathrm{mg}$ along with insulin and anti-TB during the intensive periods, while the comparison group (non-MET group) received insulin and anti-TB therapy. Patients were carried out at outpatient ward of Surabaya Paru Hospital, with criterias: (1) patient DM with a new case of TB co-infection, who were given insulin and anti-TB regimens; (2) positive AFB in sputum smear (three times assessments); (3) Patient's age was 25 to 60 years old; (4) has normal liver function and renal function; (5) not in hypoxia condition, presenting by peripheral oxygen saturation level must be higher than $92 \%$. The levels of IL-10 were measured before and after this observation period and as a clinical result, we also evaluated the smear reversion (two times smear assessments after the intensive phase of anti-TB therapy) in DM-TB co-infection patients in both of groups.

\section{Diagnosis and management therapy}

The diagnosis of TB was established by (1) clinical symptoms and signs of TB, such: chronic productive cough, unintentional weight loss; (2) positive sputum smear of acid-fast bacilli (AFB) by microscopic Ziehl-Neelsen-stained sputum slides (three times assessment and chose the highest levels of AFB); and (3) chest radiographs with suggestive features of TB.

Patients diagnosed with TB were registered and treated with antiTB for a period of 6 months in accordance to WHO guidelines $[19,20]$. Management therapy for achieving good glycaemic control was insulin therapy. These following drugs were used: MET (Metformin(R)), insulin (Humulin (R)), rifampicin (RIF), isoniazid (INH), pyrazinamide (PYR), ethambutol (ETH). MET were given 1000-1500 $\mathrm{mg}$ in the divided daily dose for at least two months or during the intensive phase of TB treatment, accompanying insulin and anti-TB.

\section{Acid Fast Bacilli smears (AFB)}

Sputum smears were stained by the Ziehl-Nielsen technique and examined by light microscopy for AFB. Sputum was collected two times: (1) before treatment in order to diagnose (three times assessment and chose the highest levels of AFB) and (2) after the intensive phase of anti-TB treatment in order to do evaluation (two times assessment and chose the highest levels of AFB). 
Page 2 of 3

\section{Cells culture and ELISA}

Cells and ELISA: PBMC was obtained from patients' whole blood and $1 \times 10^{6}$ were cultured in RPMI 1640 medium supplemented with $10 \%$ fetal bovine serum, $0.1 \mu \mathrm{g}$ mantoux and $0.7 \mu \mathrm{g}$ penicilline. Supernatant were harvested after 72 hours and prepare for ELISA methods in order to measure the levels of IFN- $\gamma$ and IL-10. ELISA. IL-10 (RnD P113058) was used as measurement kits.

\section{Result}

\section{Characteristic of patients}

This study's ethical clearance was approved by ethical committee of Surabaya Paru Hospital with no. 09.01/KERS/102.6/2016 and written informed consent obtained from all participants after information for consent was given by the investigators. During this study period, there were 476 cases of new TB infection and 156 cases ( 30\%) of that was type $2 \mathrm{DM}-\mathrm{TB}$ co-infection. 42 patients were eligible participated in these observational studies. All the basic conditions in both groups were homogeneous ( $p>0.05)$ (Table 1$)$. In order to prevent MET associated lacto acidosis (MALA) during MET therapy in this study, all patients has been determined at the following precondition criteria: (1) minimal to moderate lung lesion; (2) oxygen saturation $>92 \%$; (3) normal function of SGOT, and SGPT, and normal kidney function (BUN, Creatinine serum) (Table 1). Moreover, there was no incidence of lactic acidosis event during this observation period [21]. $100 \%$ of MET group has AFB reversion while only $75 \%$ of control group has (Table 2).

\section{Interleukin -10}

IL-10 has ability to inhibit the $\mathrm{T}$ lymphocyte production of cytokines, including IFN- $\gamma \quad[11,22,23]$. Using Wilcoxon-Mann Whitney, nonparametric statistical test, Figure 1 shows that IL-10 level before treatment between MET group and non-MET group were alike ( $p>0.005$ ), thus it shows that patients in both groups, before treatment, were in the similar stage of IL-10. Although IL-10 level was increased, the differences before and after observation period was not significant between MET and non-group ( $p>0.005$ ). Difference of interleukin-10 level pre and post observation in MET group was not significantly different from non-MET group.

\begin{tabular}{|l|l|l|l|}
\hline Parameters & MET group & $\begin{array}{l}\text { Non } \\
\text { group }\end{array}$ & $\mathbf{P}$ (difference) \\
\hline Ages (years old) & $44.59 \pm 8.64$ & $48.40 \pm 8.17$ & 0.863 \\
\hline HbA1c (\%) & $8.82 \pm 1.91$ & $9.52 \pm 2.02$ & 0.379 \\
\hline $\begin{array}{l}\text { Oxygen saturation }\left(\mathrm{SpO}_{2}\right) \\
(\%)\end{array}$ & $98.06 \pm 0.73$ & $97.47 \pm 0.83$ & 0.308 \\
\hline BUN (mg/dL) & $0.95 \pm 0.16$ & $0.93 \pm 0.13$ & 0.98 \\
\hline Creatinine serum (U/L) & $23.92 \pm 11.92$ & $27.3 \pm 12.01$ & 0.103 \\
\hline SGOT (U/L) & $17.63 \pm 6.16$ & $14.44 \pm 6.48$ & 0.354 \\
\hline SGPT (U/L) & $19.22 \pm 8.73$ & $16.09 \pm 7.56$ & 0.509 \\
\hline
\end{tabular}

Table 1: Characteristic of type 2 DM-TB co-infection during observation period of study; [Participants characteristic condition before observation periods. HbAlc was measured after 2 months observation period].

\begin{tabular}{|l|l|l|l|l|}
\hline \multirow{2}{*}{ AFB Result } & \multicolumn{2}{l|}{ MET group } & \multicolumn{2}{l|}{ Non MET group } \\
\cline { 2 - 5 } & Before (\%) & After (\%) & Before (\%) & After (\%) \\
\hline Negative & 0 & 100 & 0 & 75 \\
\hline Scanty/+1 & 40.9 & 0 & 30 & 25 \\
\hline 2 & 18.2 & 0 & 35 & 0 \\
\hline 3 & 40.9 & 0 & 35 & 0 \\
\hline Total & 100 & 100 & 100 & 100 \\
\hline Interpretation & $100 \%$ AFB Reversion & $75 \%$ AFB Reversion \\
\hline
\end{tabular}

Table 2: Acid Fast Bacilli smears result of type 2 DM-TB patients before and after observation period.

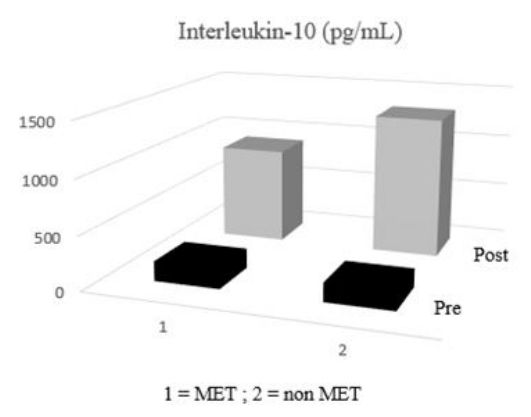

Figure 1: Interleukin (IL)-10 level of type 2 DM-TB patient before and after observation period.

\section{Discussion}

IL-10 a major anti-inflammatory cytokines plays important role in metabolic disorder such diabetes due its affect to insulin sensitivity [10]. It suppresses macrophage function and inhibits proinflammatory cytokines such IFN- $\gamma$, TNF- $\alpha$ and IL- $1 \beta$. The increase in IL-10 levels appears to support the mycobacterial survival in the host [22] due to the inhibition of autophagy targeting signals through IL-10 activated SOCS3, and then, SOCS3 inhibits the Janus kinase-2 (Jak2)/signal transducer and activator of transcription (Stat) pathway in activating macrophage autophagy $[24,25]$. In this study, the increasing of IL-10 may happen not only due to macrophage related Th-2 activation but also due to insulin attenuated anti-inflammation regulatory [10,26-28]. Based on this result, MET therapy may consider as new strategy in enhancing anti TB efficacy due to its two main ability:

- MET controlled IL-10 secretion thus alter host immune response against TB infection; and

- $\quad$ MET also affects in Insulin sensitivity.

However, the further study requires in supporting this result in a larger population's number of DM-TB co-infection patients.

\section{References:}

1. Almeida Da Silva PE, Palomino JC (2011) Molecular basis and mechanisms of drug resistance in Mycobacterium tuberculosis: Classical and new drugs. J Antimicrob Chemother 66: 1417-1430. 
Citation: Novita BD (2018) Metformin Associated Interleukin-10 Affected Insulin Sensitivity and Anti-Tuberculosis Result in Type 2 Diabetes with Tuberculosis Co-infection: A Case Report. J Clin Respir Dis Care 3: 136. doi:10.4172/2472-1247.1000136

Page 3 of 3

2. Sane GE, Schepisi M, Goletti D, Bates M, Mwaba P, et al. (2017) The global dynamics of diabetes and tuberculosis: The impact of migration and policy implications. Int J Infect Dis 56: 45-53.

3. Goldhaber-Fiebert JD, Jeon CY, Cohen T, Murray MB (2011) Diabetes mellitus and tuberculosis in countries with high tuberculosis burdens: Individual risks and social determinants. Int J Epidemiol 40: 417-428.

4. Pal R, Ansari MA, Hameed S, Fatima Z (2016) Diabetes mellitus as hub for tuberculosis infection: A snapshot. Int J Chronic Dis 2016: 1-7.

5. Abbas AK, Lichtman AH, Shiv P (2012) Cellular and Molecular Immunology 8th ed Saunders.

6. Herzmann C, Ernst M, Ehlers S, Stenger S, Maertzdorf J, et al. (2012) Increased frequencies of pulmonary regulatory T-cells in latent Mycobacterium tuberculosis infection. Eur Respir J 40: 1450-1457.

7. Marin ND, Paris SC, Rojas M, Garcia LF (2012) Reduced frequency of memory $\mathrm{T}$ cells and increased Th17 responses in patients with active tuberculosis. Clin Vaccine Immunol 19: 1667-1676.

8. Chee CB, KhinMar KW, Gan SH, Barkham TM, Koh CK, et al. (2010) Tuberculosis treatment effect on T-cell interferon-gamma responses to Mycobacterium tuberculosis-specific antigens. Eur Respir J 36: 355-361.

9. Hong E, Ko HJ, Cho YR, Kim HJ, Ma Z, et al. (2009) Interleukin-10 prevents diet-induced Insulin resistance skeletal muscle. Diabetes 58: 2525-2535.

10. Barry JC, Shakibakho S, Durrer C, Simtchouk S, Jawanda KK, et al. (2016) Hyporesponsiveness to the anti-inflammatory action of interleukin-10 in type 2 diabetes. Sci Rep 6: 21244.

11. Matsushita I, Hang NT, Hong le T, Tam do B, Lien LT, et al. (2015) Dynamics of immune parameters during the treatment of active tuberculosis showing negative interferon gamma response at the time of diagnosis. Int J Infect Dis 40: 39-44.

12. Brunton L, Chapner B, Knollmann B (2011) The pharmacological basis of therapeutics-Goodman \& Gillman-7th ed Mc Graw Hill Medical.

13. Zhou Z, Immel D, Cai-Xia Xi, Bierhaus A, Xu Feng, et al. (2006) Regulation of osteoclast function and bone mass by RAGE. J Exp Med 203: 1067-1080.

14. Katzung BG, Mastres SB, Trevor AJ (2012) Basic \& Clinical Pharmacology. Mc Graw Hill Education, Asia.

15. Li Gong, Goswami S, Giacomini KM, Russ B Altman, Teri E Klein (2013) Metformin pathways: Pharmacokinetics and pharmacodynamics. Pharmacogenet Genomics 22: 820-827.
16. Singhal A, Jie L, Kumar P, Hong GS, Leow MK, et al. (2014) Metformin as adjunct antituberculosis therapy. Sci Transl Med 6: 159-263.

17. Dallaglio K, Bruno A, Cantelmo AR, Esposito AI, Ruggiero L, et al (2014) Paradoxic effects of metformin on endothelial cells and angiogenesis. Carcinogenesis 35: 1055-1066.

18. Coyle C, Cafferty FH, Vale C, Langley RE (2016) Metformin as an adjuvant treatment for cancer: A systematic review and meta-analysis. Ann Oncol 27: 2184-2195.

19. Menzies D, Sterling TR (2014) Treatment of mycobacterium tuberculosis infection: Time to get a move on? Ann Intern Med 161: 449.

20. Van Deun A, Jose A Caminero (2013) Guidelines for clinical and operational management of drug-resistant tuberculosis. International union against tuberculosis and lung disease, France.

21. Novita BD, Pranoto A, Wuryani Soediono EI, Mertaniasih NM (2017) A case risk-study of lactic acidosis risk in metformin use in type 2 diabetes mellitus tuberculosis co-infection patients. Indian J Tuberc.

22. Cavalcanti YV, Brelaz MC, Neves JK, Ferraz JC, Pereira VR (2012) Role of TNF-alpha, IFN-gamma, and IL-10 in the development of pulmonary tuberculosis. Pulm Med 2012: 745483.

23. Singhal J, Agrawal N, Vashishta M, Priya NG, Tiwari BK, et al. (2012) Suppression of dendritic cell-mediated responses by genes in calcium and cysteine protease pathways during Mycobacterium tuberculosis infection. J Biol Chem 287: 11108-11121.

24. Lin C, Chien SY, Chen CL, Hsieh CY, Tseng PC, et al. (2015) IFN- g induces mimic extracellular trap cell death in lung epithelial cells through autophagy-regulated DNA damage. J Interf Cytokine Res 36: 1-13.

25. Lin C (2017) Escape from IFN- $\gamma$-dependent immunosurveillance in tumorigenesis. J Biomed Sci 24: 1-9.

26. Dobrian D, Ma Q, Lindsay JW, Leone KA, Ma K, et al. (2011) Dipeptidyl peptidase IV inhibitor sitagliptin reduces local inflammation in adipose tissue and in pancreatic islets of obese mice. Am J Physiol Endocrinol Metab 300: 410-421.

27. Clark I, Atwood C, Bowen R, Paz-filho G, Vissel B (2012) Tumor necrosis factor-induced cerebral insulin resistance in alzheimer's disease links numerous treatment rationales. Pharmacol Rev 64: 1004-1026.

28. Hartman ME, O'Connor JC, Godbout JP, Minor KD, Mazzocco VR, et al. (2004) Insulin receptor substrate-2-dependent interleukin-4 signaling in macrophages is impaired in two models of type 2 diabetes mellitus. J Biol Chem 279: 28045-28050. 